\title{
PERFORMANCE COMPARISON OF TIMBER-BASED ASSEMBLIES AND OTHER CONSTRUCTION SOLUTIONS FOR ROOFTOP EXTENSIONS
}

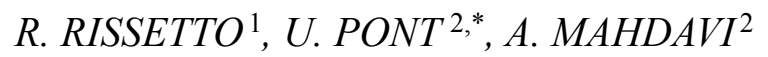 \\ ${ }^{1}$ Master Programme Building Science and Technology, TU Wien, Vienna, Austria \\ ${ }^{2}$ Department of Building Physics and Building Ecology, TU Wien, Karlsplatz 13, 1040 Vienna, Austria \\ *E-mail: ulrich.pont@tuwien.ac.at
}

\begin{abstract}
Population growth in a number of central European cities necessitates the creation of additional living spaces within the existing urban settings. Toward this end, densification via rooftop extension of existing buildings can provide a partial solution. As the requirements regarding energy performance, summer-time thermal comfort, and structural integrity of attic expansions have been increasingly tightened, planners must carefully assess the advantages and disadvantages of different construction possibilities. Focusing specifically on timber construction as a kind of reference, the present contribution includes a comparison of six different (both conventional and novel) construction solutions for roof top extensions in view of different performance criteria, such as ecological footprint, impact on energy indicators, summer overheating mitigation, cost, and construction time. To conduct the comparison in a transparent manner, the selected construction methods were virtually applied to a case-study building and assessed via multiple tools, including a numeric thermal simulation application.
\end{abstract}

Keywords: rooftop extension, building performance, timber construction, ecological footprint, decision support

\section{Introduction}

Urban densification is currently considered as not only a possibility, but an urgent requirement to handle the city growth happening in Central European metropoles. Thereby, different strategies in research and realizations are explored. For instance, Pirstinger et al. investigated the principal urban densification potential based on different biological, physical and human-related factors [1]. Moreover, they estimated the impact of different performance indicators on building and urban level, for instance the change in energy consumption. Regarding the potential of roof-top extensions, different studies emphasize the large spatial reserve given in the non-extented rooftops of the building stock of Central European cities. In the city of Vienna, for instance, a study from 2004 [2] reckons that around 400 rooftop extensions per year are built, and that there is a remaining potential of 30.000 to 40.000 apartments in the attic spaces of Gründerzeit buildings (these are regularly historistic buildings erected until
1918). Figure 1 illustrates the statistics of this study. A more recent study from 2013 identifies a number of 3600 residential units to be realized via rooftop extension until 2035 in Vienna [3]. Without doubt, the construction of rooftops plays an important role on an urban development level. Thus, the construction processes are worth to take a closer look. Different aspects in planning of rooftop extensions need to be considered, for instance people (existing and future occupants of the building, neighbours), legal documents (laws and standards), economic aspects, traffic situation, and building location. Coydon et al. [4] suggest a user friendliness concept for rooftop extension building sites to mitigate negative impacts of the construction activities. Moreover, aspects of building performance, such as heating demand, summer overheating tendency, noise insulation, and others have to be carefully integrated in planning and realization processes. These aspects can be considered as of highest importance, given that many positive and negative aspects of these performance criteria have directly to do with

This is an open-access article distributed under the terms of the Creative Commons Attribution-NonCommercial 4.0 International License (https://creativecommons.org/licenses/by-nc/4.0/), which permits unrestricted use, distribution, and reproduction in any medium for non-commercial purposes, provided the original author and source are credited, a link to the CC License is provided, and changes - if any - are indicated. 


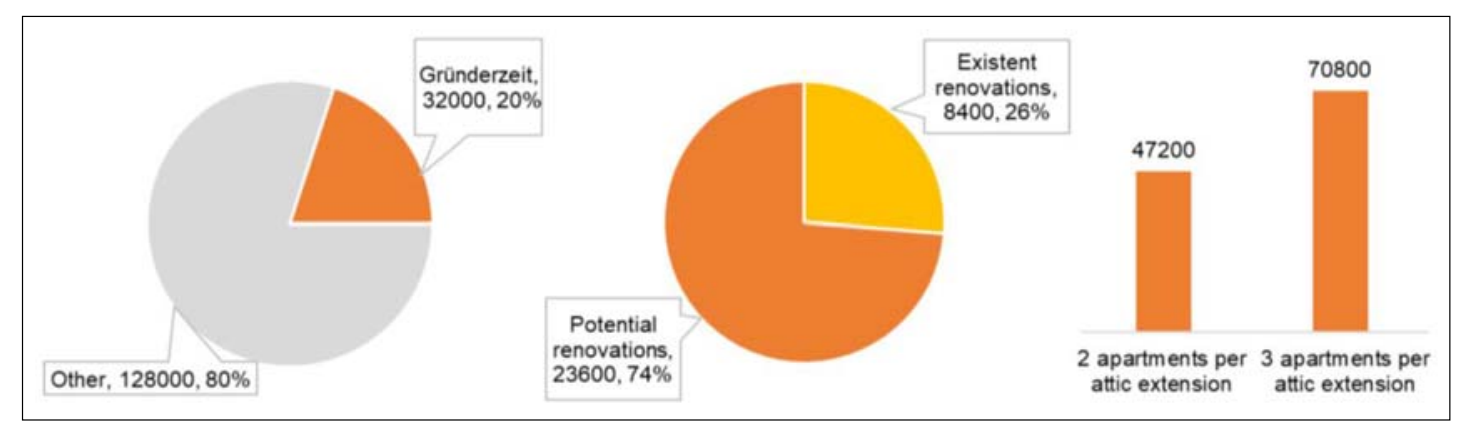

Fig. 1. Statistics form [2]: Habitation in Vienna and historical buildings (left), attic renovations (center), potential apartment (right) (based on data from [2])

the roof. Yew et al. [5] illustrate that $70 \%$ of a building's heat gain happens via the roof, mainly via solar radiation. Needless to say, this has to be considered carefully during planning. Construction materials that improve the rooftop's and the overall building's energy performance are a critical necessity today, on the one hand to fulfil the ever-tightening requirements regarding different KPIs (Key Performance Indicators), on the other hand to ensure thermal comfort for the future inhabitants. Pacheco-Torgal [6] reckons that the impact of climate change will presumably result in a shift from large heating demands to large cooling demands for buildings in temperate climates. Wurm et al. [7] suggest that the user behaviour plays a very important role regarding several aspects of building performance; however different construction systems may influence these building performance aspects as well.

This contribution illustrates the efforts of a recently completed master thesis [8] that focussed on a critical assessment of different, commonly used rooftop construction styles and their advantages and disadvantages. Thereby, a Gründerzeit building that was subjected to a rooftop extension was employed as virtual testing framework for different construction typologies. The constructions were mapped onto the rooftop's principal extension plan. Subsequently, these different construction scenarios were evaluated regarding their thermal performance (heating and cooling demand, indoor thermal comfort), their acoustical performance, their ecological footprint, and regarding construction-related criteria (cost, time, and mounting effort). Moreover their weight was considered, as this is of fundamental importance regarding structural stability and integrity of the building below the rooftop.

\section{Methodology}

\subsection{The reference building}

A typical Viennese Gründerzeit building was employed as case study building. This building was originally erected in 1889 and is located in central Vienna (6th district). It has 5 floors, and has a maximum height of around 28 meters. Figure 2 illustrates the building's urban surroundings, while Fig. 3 shows the floor plans of the two roof-top extension levels, and correspond-

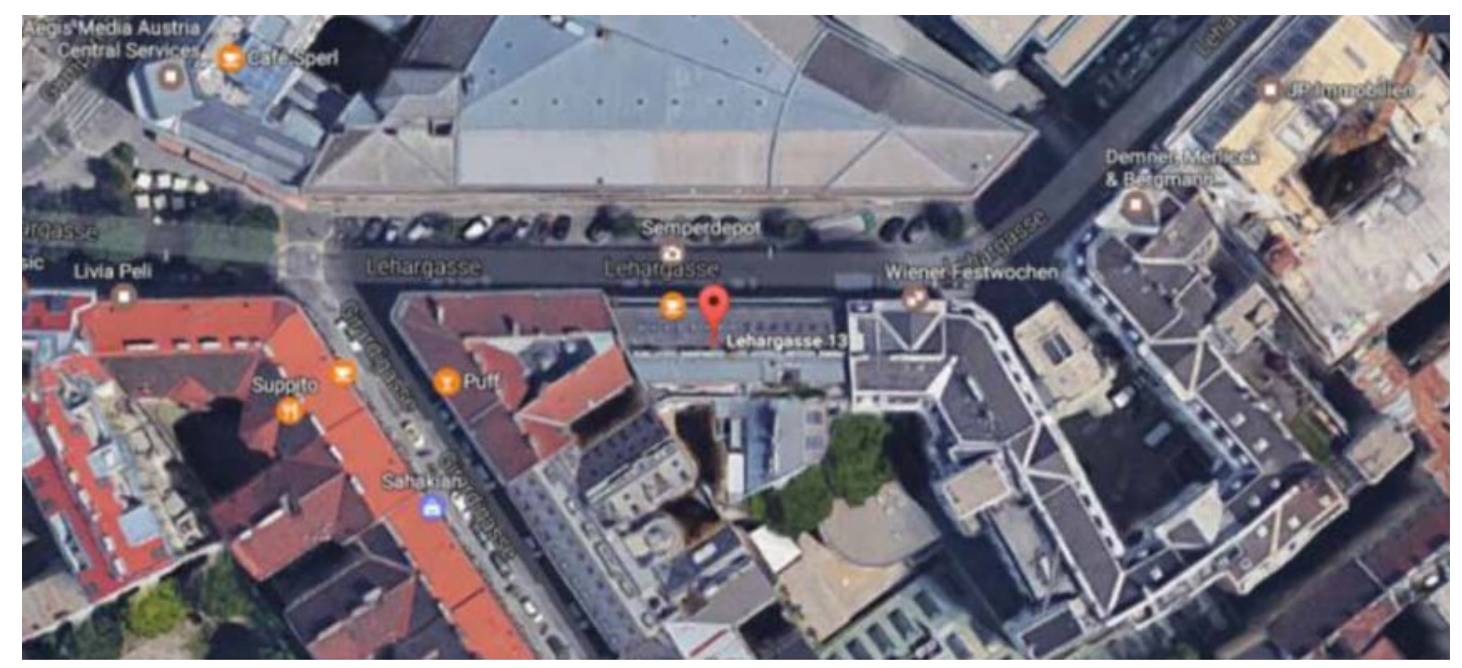

Fig. 2. Site plan of the case study building in the 6th district of Vienna (building is highlighted with a marker; taken from Google maps) 


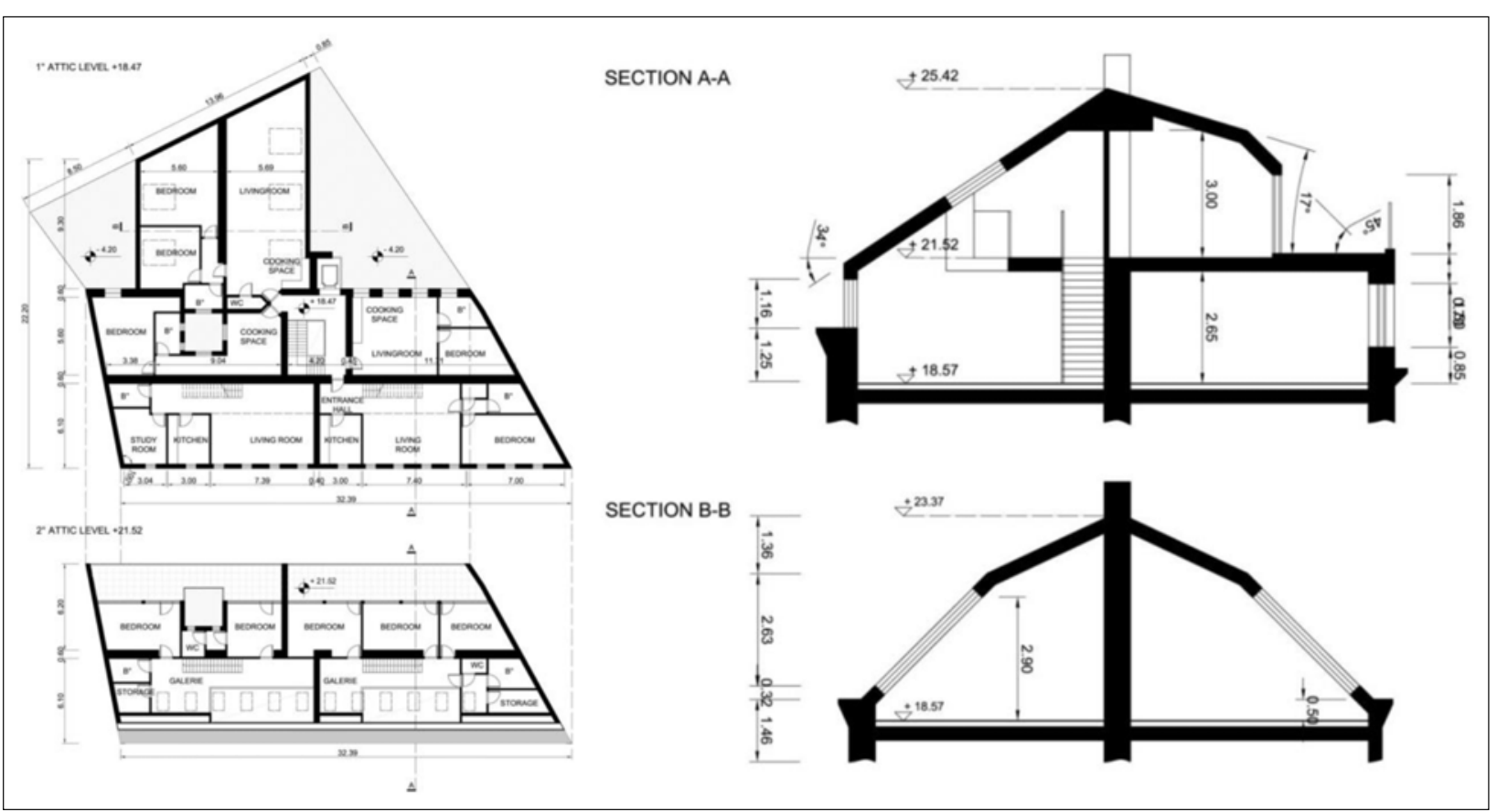

Fig. 3. Floor plans (left), and sections (right) of the case study building's roof top extension

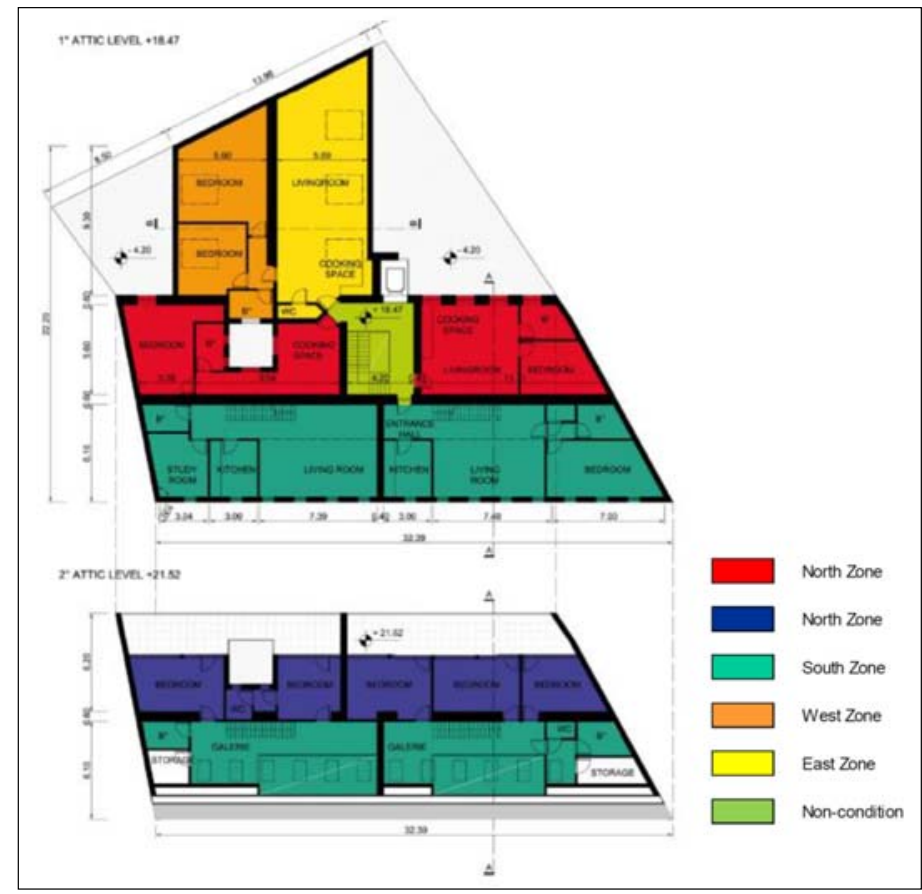

Fig. 4. Zoning of the two rooftop floors

ing sections. The rooftop extension includes residential units of different spatial extension and dimension, some of them spanning over both rooftop floors. The rooftop extension was realized in 1998. The attic space was divided in six evaluation zones for the purpose of this study. These zones were constituted by the two residential units in the roof top, their state of conditioning, and their cardinal orientation. Figure 4 illustrates the zoning of the attic space.

\subsection{Assessed constructions}

The different constructions applied virtually in the rooftop extension geometry mainly differ in load-bearing structure and insulation material, while they all have similar finishing setups. Altogether six different construction typologies were examined. Thereby, the constructions were assumed to form the thermal envelope (steep roof) above the 


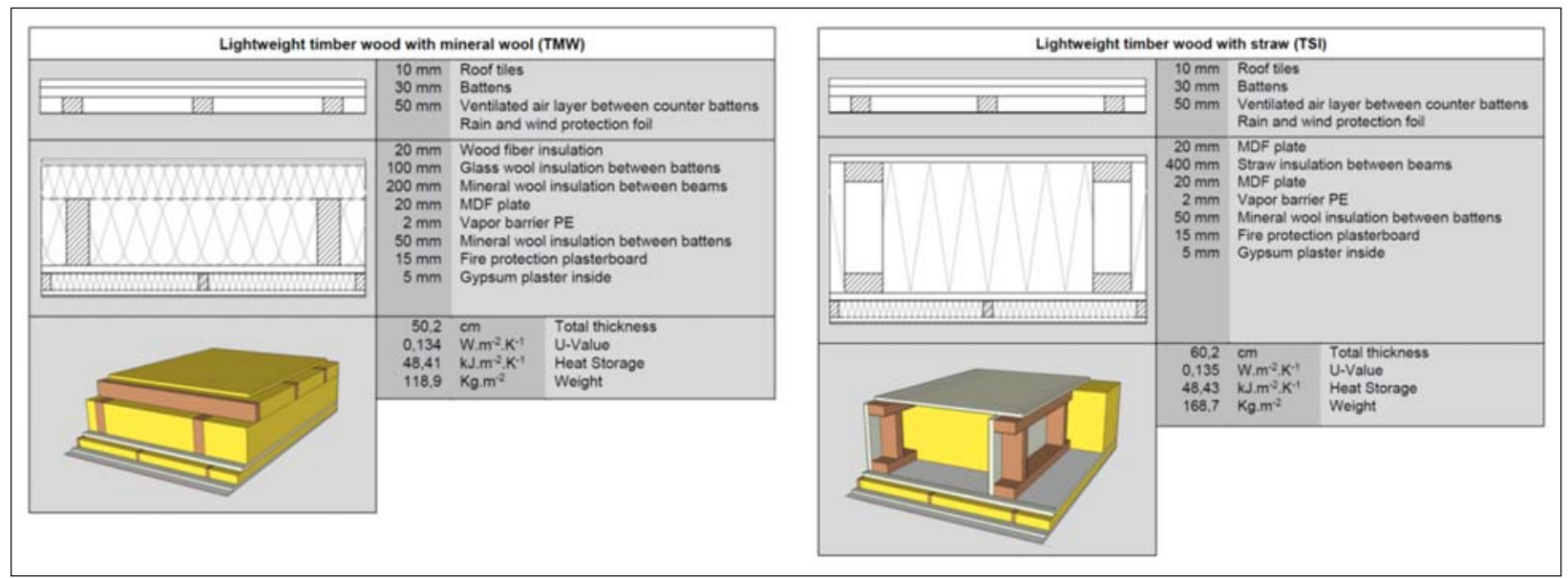

Fig. 5. Lightweight timber constructions TMW (left) and TSI (right)
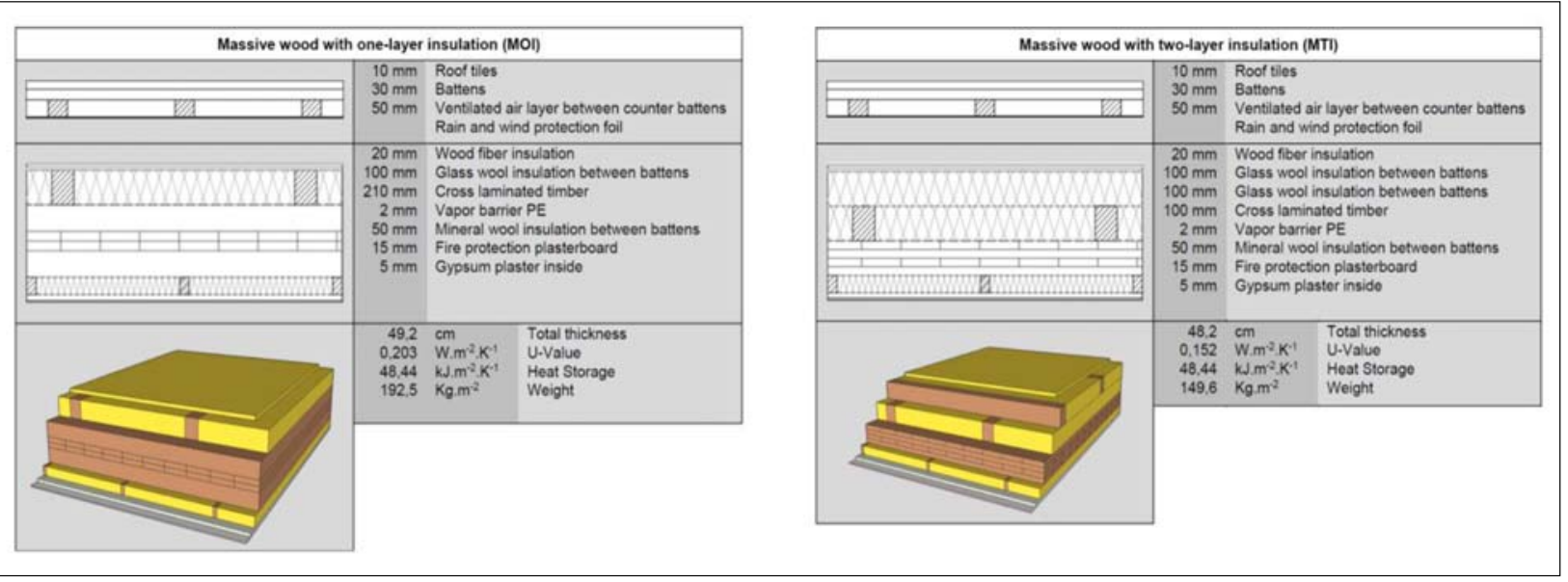

Fig. 6. Massive timber constructions MOI (left) and MTI (right)

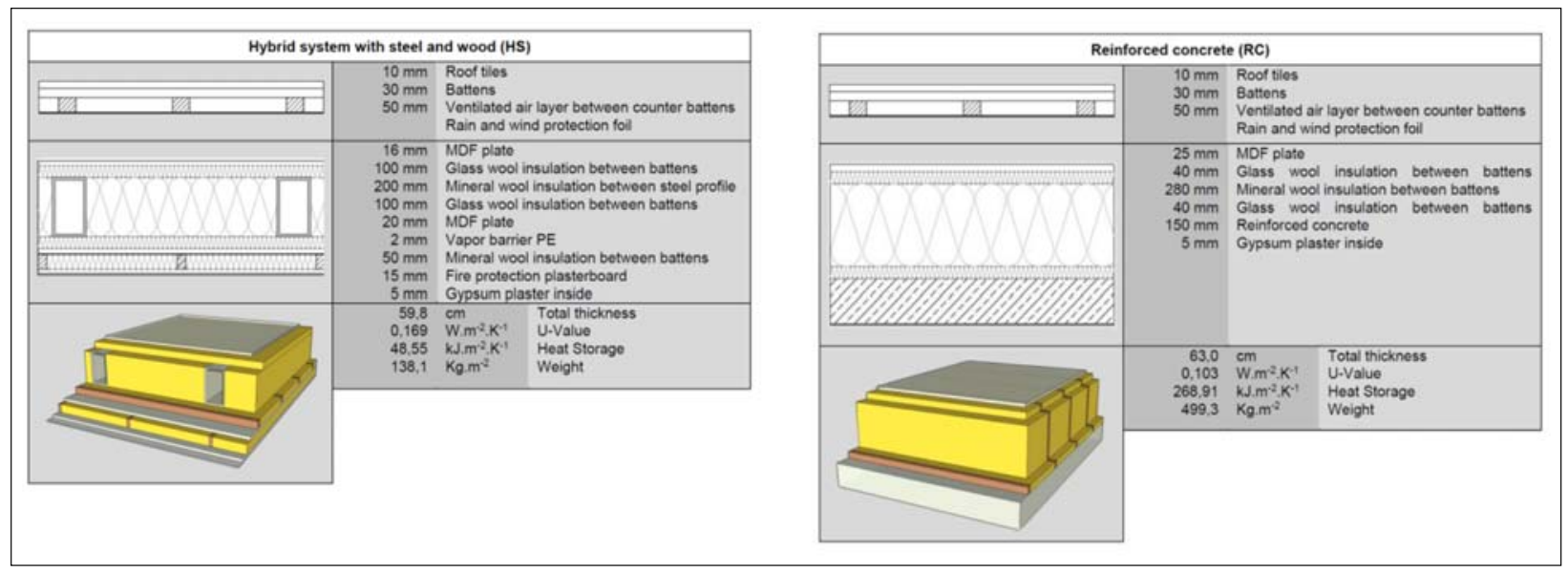

Fig. 7. Constructions HS (left, hybrid system) and RC (right, concrete construction)

upmost slab of the existing building (which still is the original Dippelbaumdecke, a massive construction of adjoined wooden trusses, with slight modifications). The construction systems include lightweight timber constructions (constructions TMW and TSI), massive timber construction (MOI and
MTI), a hybrid construction system (combination of steel and wood, HS), and a concrete construction (RC). Figures 5-7 illustrate the layer sequence of the different systems, and some key data of the overall construction, such as weight, height storage capacity, and $U$ value. 
Table 1. Ventilation rates (window ventilation, no economizer)

\begin{tabular}{ccl}
\hline & \multicolumn{2}{c}{ Ventilation rate $\left[\mathrm{h}^{-1}\right]$} \\
\cline { 2 - 3 } $\begin{array}{c}\text { Daytime } \\
\text { (until h) }\end{array}$ & $\begin{array}{c}\text { Summer } \\
\text { (ONORM 8110-3:2012) }\end{array}$ & $\begin{array}{c}\text { Winter } \\
\text { (Passivhaus Institut) }\end{array}$ \\
\hline 9:00 & 0.56 & $\begin{array}{l}2 / 24 \mathrm{hs} ; 6 \mathrm{~h}^{-1} \text { in } 10 \mathrm{~min} \\
\text { 15:00 }\end{array}$ \\
$19: 00$ & 0.14 & $\begin{array}{l}(8: 00-8: 10 ; \\
17: 00-17: 10)\end{array}$ \\
\hline
\end{tabular}

\subsection{Performance assessment}

Different performance evaluations were performed for the rooftop-extension, including heating demand, cooling demand and summer overheating tendency via numeric building simulation (Energyplus [9]). Ecological footprint based on the Austrian OI3 method [10], and cost and construction time evalua- tion, based on reference literature [11]. Input data assumptions, such as ventilation rates, internal gains, weather data files, for the thermal building performance assessment were chosen in accordance to typical Austrian standards (for instance [12]). Ventilation assumptions included both natural window ventilation, as well as the use of a ventilation economizer. The former were based on Austrian standards [12] for summer time and recommendations of the Passivhaus Institut [13] for winter periods (Table 1), the latter were based on an algorithm, allowing up to an air change rate of $8 \mathrm{~h}^{-1}$ in case the outside air is cooler then the indoor air. Regarding the cost and construction time assessment focussed on load-bearing elements and insulation material. Roof classing and water proofing was not considered, as it is similar in all examined constructions. Likewise, identical elements of the roof top extensions, such as windows, installations, and interior construction works

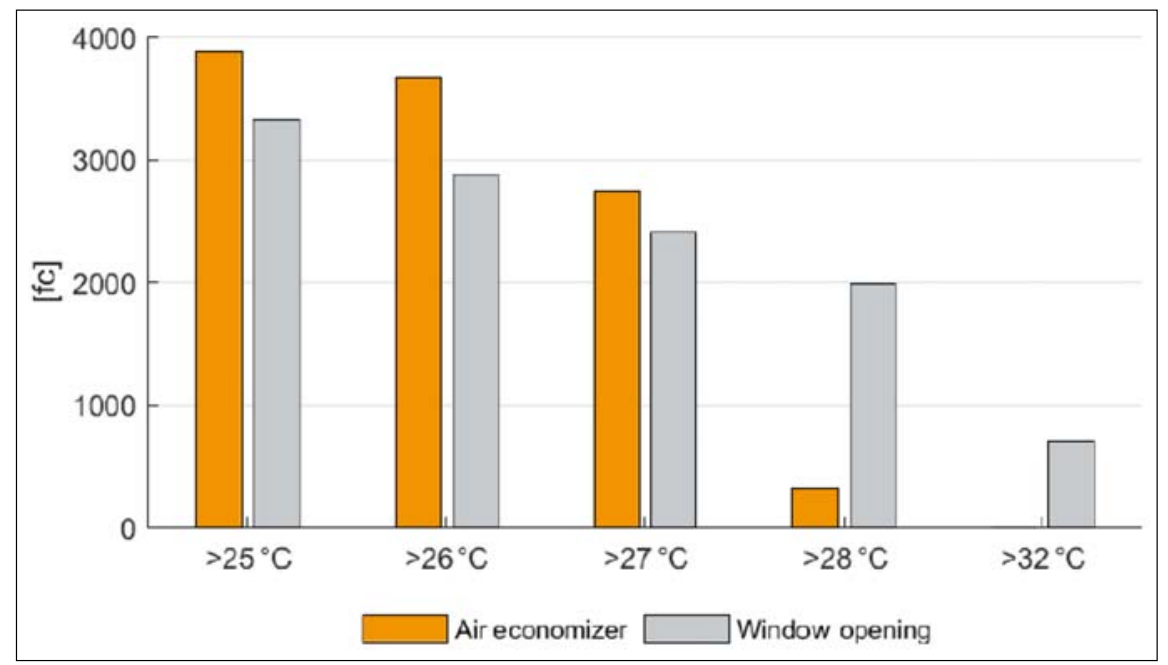

Fig. 8. Temperature frequency in summer period for window ventilation model and economizer model, west zone, TMW-construction

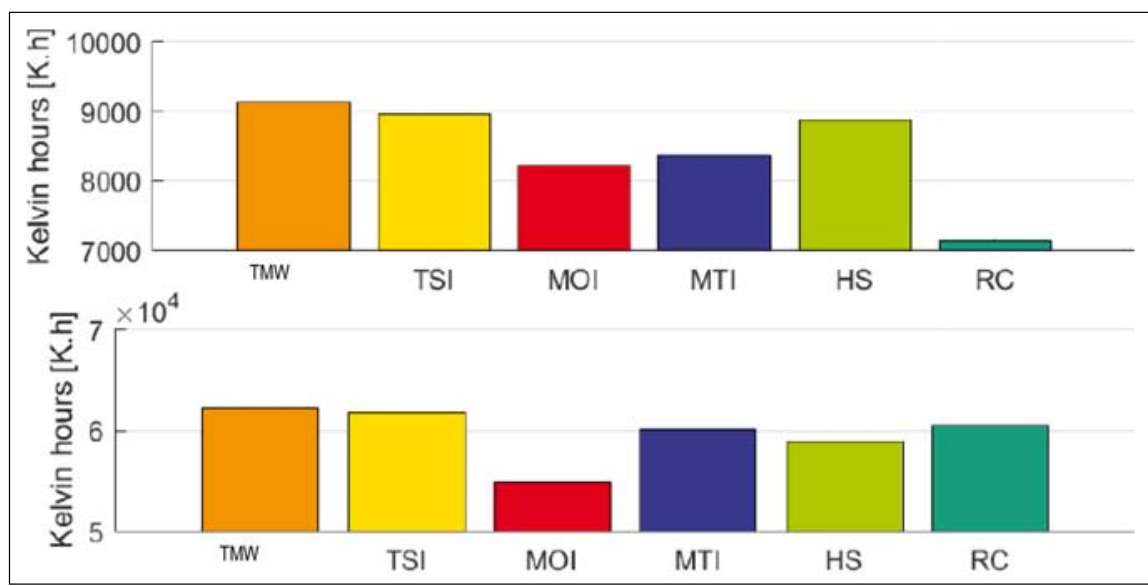

Fig. 9. Temperatures above $28^{\circ} \mathrm{C}$ expressed in Kelvin hours for the summer period in the west zone. Model with air economizer (top) and with window operation (bottom) 


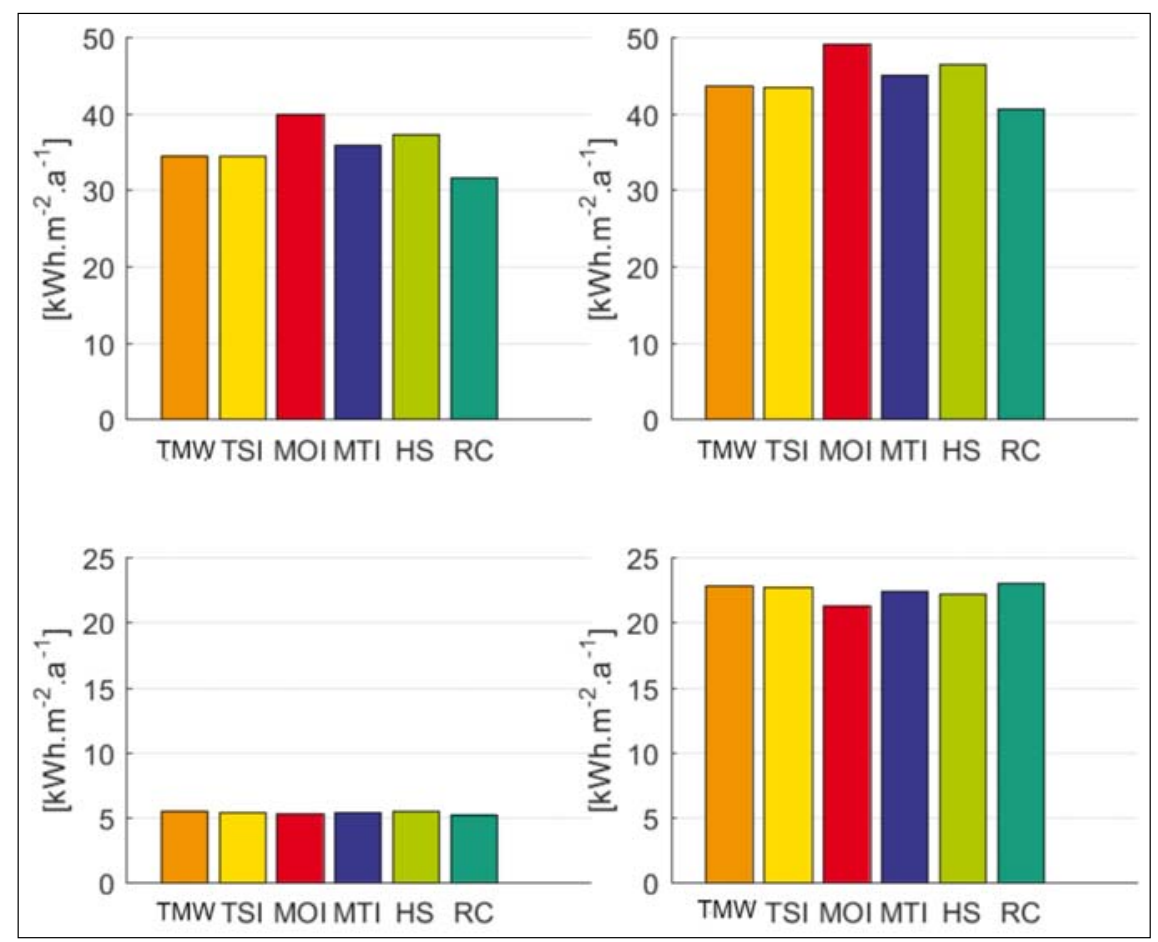

Fig. 10. Heating demand (top) and cooling demand (bottom) for ventilation with air economizer (left) and window ventilation (right)

were omitted from the evaluation. The full reference of input data assumptions and model settings can be found in [8].

\section{Results and discussion}

\subsection{Thermal performance and window operation vs. economizer}

Prior to further investigation, a comparison between the two different ventilation schemes (window ventilation versus economizer) was evaluated. Therefore, simulation runs with the construction TMW were conducted. Figure 8 illustrates the temperature frequencies for the west zone.
Interestingly, the economizer model performs worse than window operation if $25{ }^{\circ} \mathrm{C}$ is considered as overheating threshold, however, it performs significantly better in higher temperature ranges, where window operation shows a weak performance (this, however, is a known fact in literature). Subsequently, both scenarios have been applied to all construction TMW system models. Figure 9 compares the performance of the west zone for both models for all six construction alternatives in Kelvin hours above $28{ }^{\circ} \mathrm{C}$. Generally speaking, the air economizer model performs better than the natural ventilation model. The hybrid and concrete models show strong deviations between the two models: While the air economizer model shows little overheating tendency for the concrete system, the

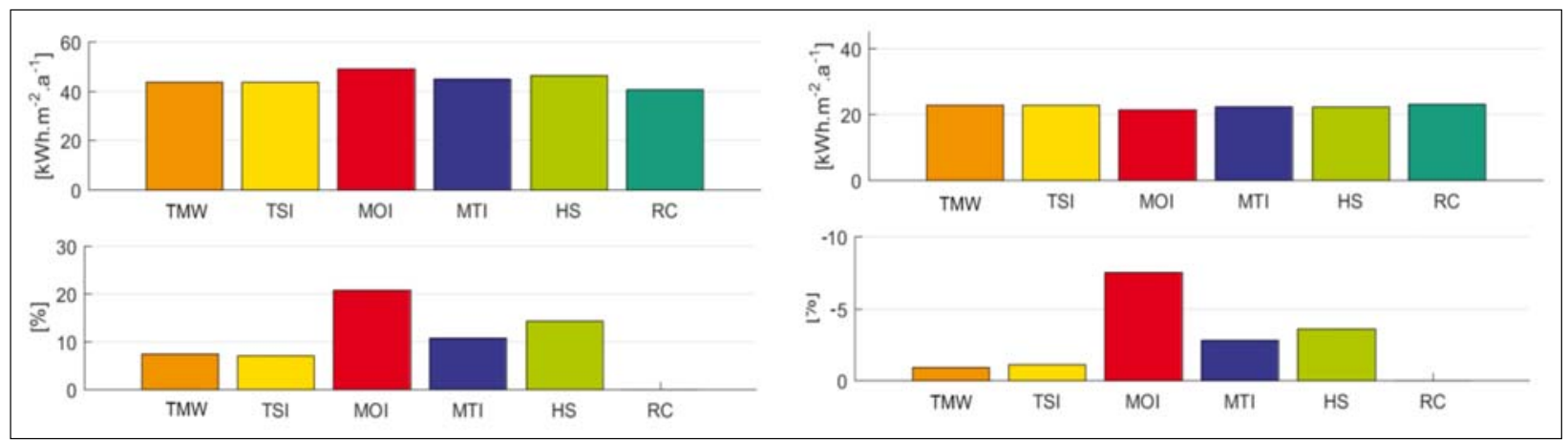

Fig. 11. Heating demand (top left) and relative deviation of the heating demand from the RC case (bottom left). Cooling demand (top right) and relative deviation of the cooling demand from the RC case (bottom right). Note that these graphs are based on window ventilation and that the $\mathrm{RC}$ has the lowest heating demand, but the highest cooling demand 


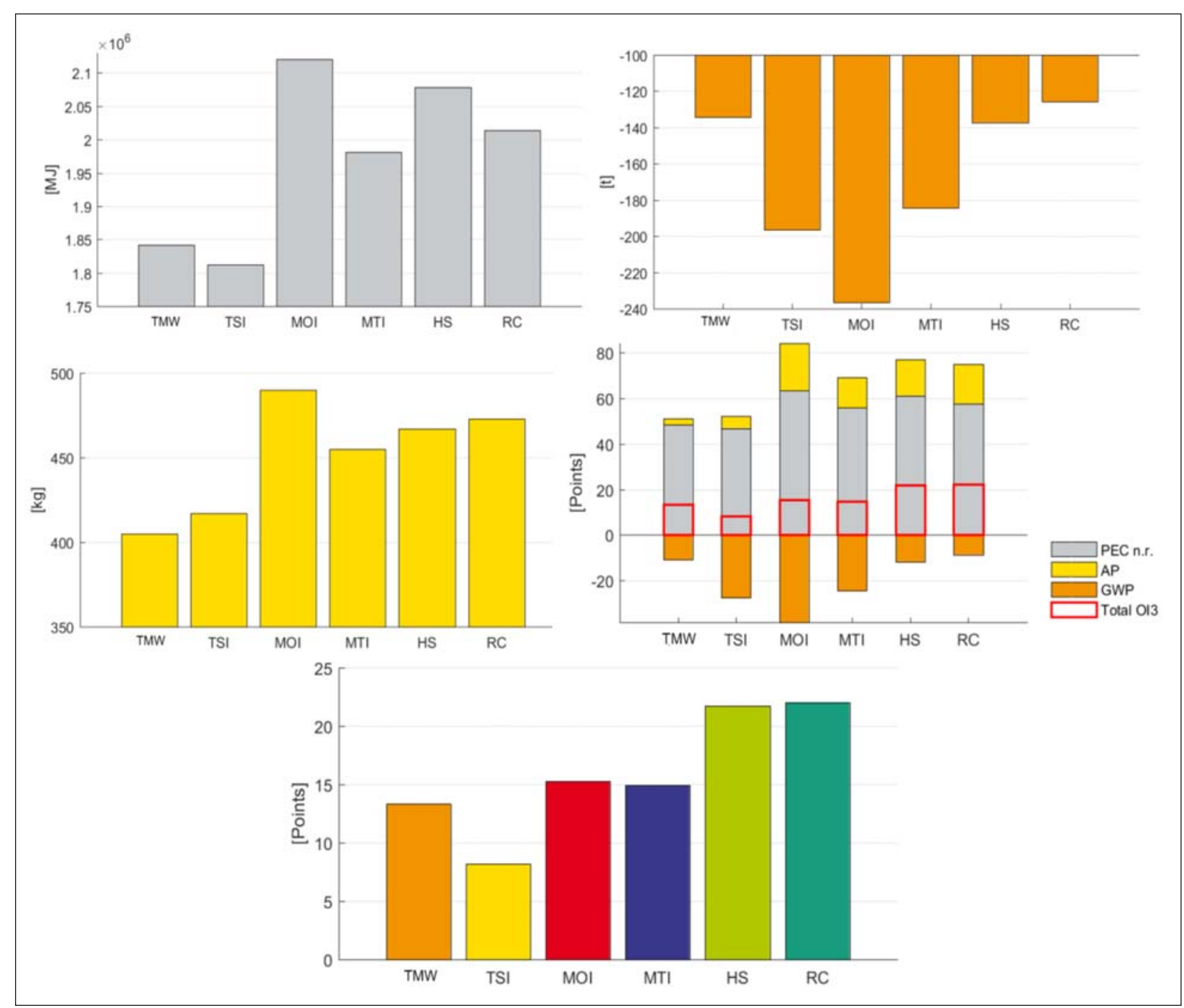

Fig. 12. PECnr (top left) in Megajoule, GWP (top right) in tons $\mathrm{CO}_{2}$-equivalent, $\mathrm{AP}$ (middle left) in $\mathrm{kg} \mathrm{SO}_{2}$-equivalent, and OI3point scale (middle right, bottom) for each of the constructions

hybrid system performs better than the timber systems in case of natural ventilation.

Figure 10 illustrates the annual heating and cooling demand for both window ventilation and economizer ventilation. There is a certain impact in case of the heating demand, but it is not as significant as the difference for the cooling demand.

Figure 11 illustrates the relative deviation of the heating and cooling demand in comparison to the reinforced concrete construction for the window ventilation scenario.

\subsection{Ecological performance}

The OI3 index is constituted by three part indicators, namely the primary energy content non-renewable (PECnr), the Global Warming Potential (GWP), and the Acidification Potential (AP). These indicators are expressed in a point scale (the higher the val- ue, the larger the environmental footprint is considered). Figure 12 illustrates the PECnr in MJ, the GWP in tons $\mathrm{CO}_{2}$-equivalents, and the $\mathrm{AP}$ in $\mathrm{kg} \mathrm{SO}_{2}$-equivalents. Moreover, the influence of each of the three part indicators onto the full point scale is presented. The light weight timber construction does perform well regarding PECnr, while the massive timber construction MOI does show very good values for the GWPscale, but rather bad values for the AP scale. In the overall scale, the hybrid and the concrete constructions show the largest values and thus the largest environmental footprint.

\subsection{Cost and construction time evaluation}

Figures 13 and 14 illustrate the cost and the working time required for each of the constructions (normalized by $1 \mathrm{~m}^{2}$ construction area). As a seventh scenario, precast concrete construction (PC) was added. This 


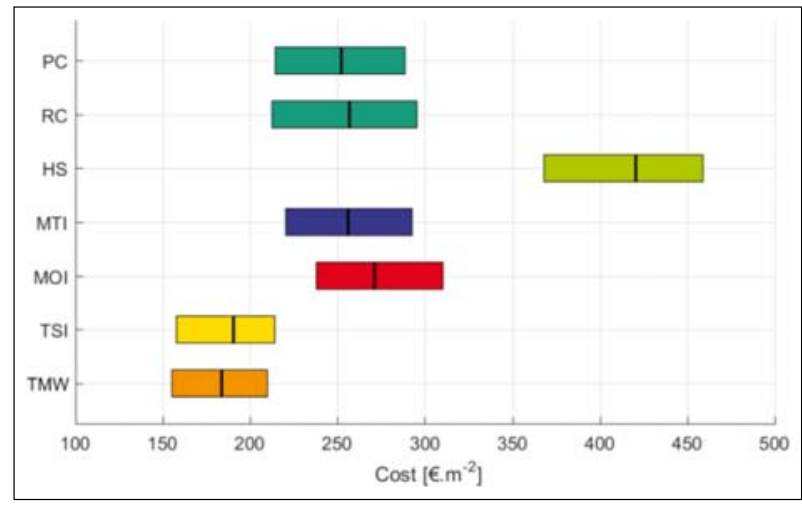

Fig. 13. Cost estimation of each construction per $\mathrm{m}^{2}$ (ranges from minimum to maximum cost, and average indicator)

construction corresponds to $\mathrm{RC}$, but assumes the use of prefabricated concrete parts instead of poured-inplace concrete. The hybrid construction reveals itself as the most time and cost intensive construction, while timber construction seems to be both fast, and fairly inexpensive, based on the evaluation via cost- and work-intensity catalogues.

\section{Conclusion and future research}

The present contribution examined six different constructions suitable as principle construction systems for rooftop extension. Results reveal that each of the constructions has strong and weak sides. For instance, the concrete construction performed very well in view of summer overheating avoidance, in comparison to other constructions of lower specific heat. On the other side, timber construction has strong points in construction cost and environmental footprint. The presented study should be understood as exemplary. It is important to point towards the limitations of the presented study: The presented results encompass the application of these constructions on one reference rooftop extension. The balance of the different key performance indicators might be different, if the set of examined buildings would be enlarged, especially regarding thermal performance and ecological footprint. Moreover, the uncertainties connected with some of the used input data have to be emphasized: We assumed a certain occupant behaviour regarding ventilation and internal gains; in reality, this might be different. Moreover, the input data for cost, time, and ecological evaluation was taken from catalogues that suggest typical values, but in reality this might deviate in different rooftop extension projects.

Nonetheless, the results provide certain hints regarding the performance of the different construction systems. Needless to say, the next steps encompass a larger rooftop and construction sample, the inclusion of adjacent building components, and opinion led by

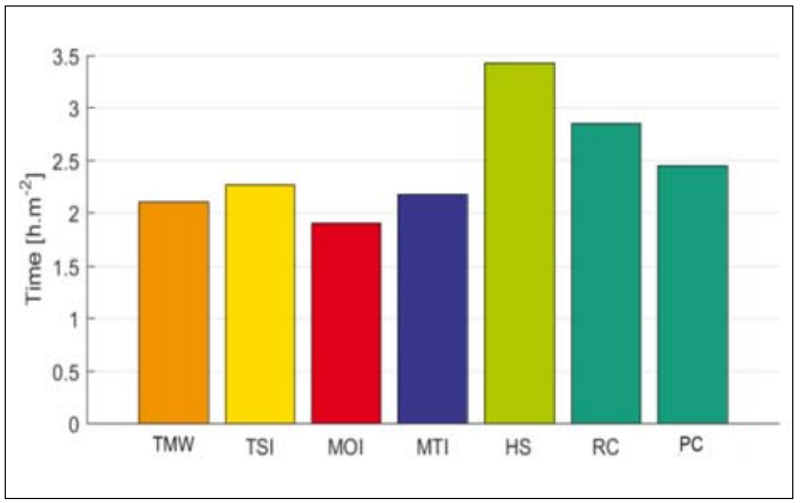

Fig. 14. Construction time estimation for each construction per $\mathrm{m}^{2}$

different stakeholders, who might increase the information depth provided in this study. Integration in Decision Support Systems, such as SEMERGY [14], is also an envisaged idea.

\section{Acknowledgements}

This paper and the corresponding master thesis were in part inspired by the COGENT-project idea, first suggested by Pont et al. [15].

\section{References}

[1] Pirstinger I., Vuckovic M., Majcen M., Raudaschl M., Tauber C., Mahdavi A., Kiesel K., Glawischnig S. (2017), EPIKUR-Energieeffizienz-Potential intelligenter Kernverdichtung des urbanen Raums. Final Report of the research project EPIKUR for the Austrian Research Promotion Agency (FFG).

[2] Stadtentwicklung Wien, Magistratsabteilung 18 (2004), Draufsetzen. 19 Dachausbauten realisiert/projektiert. Available via: https:/www.wien.gv.at/stadtentwicklung/ studien/pdf/b007503.pdf (last accessed May 2018).

[3] Kohoutek R. (2013), Wohnbau macht Stadt - Kommunale Wohnungspolitik als städtisches Gestaltungsinstrument. Endbericht - im Auftrag MA50 - Refereat Wohnbauforschung und internationale Beziehungen. Available via: http://www.wohnbauforschung.at/index.php?inc=download\&id=5861 (last accessed May 2018).

[4] Coydon F., Herkel S., Kuber T., Pfafferott J., Himmelsbach S. (2015), Energy performance of façade integrated decentralised ventilation systems. Energy and Buildings, 107, 172-180. DOI: 10.1016/j.enbuild.2015.08.015.

[5] Yew M. C., Ramli Sulong N. H., Chong W. T., Poh S. C., Ang B. C., Tan K. H. (2013), Integration of thermal insulation coating and moving-air-cavity in a cool roof system for attic temperature reduction. Energy Conversion and Management, 75, 241-248. DOI: 10.1016/j.enconman.2013.06.024.

[6] Pacheco-Torgal F. (2014), Eco-efficient construction and building materials research under the EU Framework Programme Horizon 2020. Construction and Building Ma- 
terials, 51, 151-162. DOI: 10.1016/j.conbuildmat.2013. 10.058 .

[7] Wurm A., Pont U., Tahmasebi F., Mahdavi A. (2016), Overheating risk in buildings: A case study of the impact of alternative construction solutions and operational regimes; in: In: Proceedings of CESB 2016: Central Europe towards sustainable building 2016 - Innovations for sustrainable future, P. Hájek, J. Tywoniak, A. Lupisek (Hrg.), Prague, Czech Republic, ISBN: 9788027102488; Paper-Nr. 1319 (pp. 1325-1332), 8 P.

[8] Rissetto R. P. (2018), Evaluation of wood constructions' performance for rooftop extensions. Supervisors: A. Mahdavi, U. Pont; Institute for Architectural Sciences, Department of Building Physics and Building Ecology, 2018; Defense: 25.04.2018.

[9] EnergyPlus - https://energyplus.net

[10] IBO - Österreichisches Institut für Bauen und Ökologie GmbH (2016): OI3-Indikator - Leitfaden zur Berechnung von Ökokennzahlen für Gebäude. Available via https:// www.baubook.at/m/Daten/Bilder/Infos/OI3_Leitfaden V3.1__Stand_Maerz_2016.pdf (last accessed: May 2018)
[11] WEKA (Ed.) (2014), SirAdos Kalkulationsatlas 2014 für Roh- und Ausbau im Neubau. Germany: WEKA MEDIA $\mathrm{GmbH} \& \mathrm{Co}$. KG.

[12] Austrian Standards Standard Series ÖNORM B 8110: Wärmeschutz im Hochbau - Austrian Institute of Standardisation (ÖNORM) - Heinestraße 38, 1020 Vienna, Austria

[13] Passivhaus-Institut - PHPP (Information available via www.passiv.de (last accessed: May 2018).

[14] Pont U. (2014), A comprehensive approach to web-enabled optimization-based decision support in building design and retrofit. Evaluation: A. Mahdavi, M. E. Ilal, C. Kühn; Institute for Architectural Sciences, Department of Building Physics and Building Ecology, 2014, Rigorosum: 15.09.2014.

[15] Pont U., Swoboda S., Waldmayer F. (2016), COGENT Construction Generation \& Assessment Tool - Research proposal for the EXCITE-Initiative, Faculty of Architecture and Planning, TU Wien, $47 \mathrm{p}$. 